\title{
Guttaflow Bioseal as Monocone Obturation Technique: A Scanning Electron Microscopy Study
}

\author{
Mustaffa $\mathrm{M}^{\mathrm{a}^{*}}$, Nordin $\mathrm{N}^{\mathrm{b}}$, Embong $\mathrm{SNH}^{\mathrm{b}}$, Mohd Ibrahim $\mathrm{MS}^{\mathrm{c}}$ \\ ${ }^{a}$ Department of Restorative Dentistry, Kulliyyah of Dentistry, International Islamic University Malaysia, Pahang, Malaysia. \\ ${ }^{b}$ Undergraduate dental students, Kulliyyah of Dentistry, International Islamic University Malaysia, Pahang, Malaysia. \\ ${ }^{c}$ Department of Dental Public Health, Kulliyyah of Dentistry, International Islamic University Malaysia, Pahang, Malaysia.
}

\section{ABSTRACT}

INTRODUCTION: This study compared the obturated surface area, the extrusion of root filling material beyond the apical foramen and the duration of obturation procedure in single-rooted mandibular premolar using monocone obturation technique. MATERIALS AND METHODS: The root canal of twenty single-rooted mandibular premolars were prepared, and then divided into two groups; Group 1 (GuttaFlow Bioseal (GFB) and a guttapercha (GP) cone) and Group 2 (RoekoSeal Automix root canal sealer and a GP cone). The obturation procedure was timed and the obturation radiograph was taken after the procedure. The roots were sectioned perpendicularly and the surfaces were observed under scanning electron microscope. The images were transferred to the SketchAndCalc Area Calculator software for evaluation of the obturated surface area. RESULTS: The median score of obturated surface area in Group 1 and 2 at the apical was 86.51 and 83.00, at the middle was 90.48 and 87.35 and at the coronal was 93.00 and 83.39 , respectively. The extrusion of root filling material between two groups did not show statistically significant difference. The mean duration of obturation in Group 1 and 2 was 149.50 and 137.60, respectively. CONCLUSIONS: The obturated surface area at the apical and middle root regions in Group 1 and 2 was comparable but at the coronal region, Group 1 showed 11.5\% better coverage. The extrusion of root filling material in Group 1 and 2 was equivalent. Obturation procedure in Group 1 took 8.6\% longer than in the Group 2.

KEYWORDS: GuttaFlow Bioseal; Monocone obturation technique; Hyflex CM rotary files; Scanning electron microscopy.

\section{INTRODUCTION}

Following the completion of chemomechanical debridement, the root canal is obturated with root filling material to further diminish the chances of growth of microorganisms. There are various techniques for obturating the root canal system such as cold and warm lateral compaction, continuous and interrupted waves of vertical compaction, thermo-mechanical compaction, carrier-based techniques and single cone techniques. ${ }^{1-3}$

Corresponding Author:

Asst. Prof. Dr. Musliana Mustaffa

Kulliyyah of Dentistry,

International Islamic University Malaysia,

25200 Kuantan, Pahang, Malaysia.

Tel No: +609-5705500

E-mail : muslianamustaffa@iium.edu.my,

drmusliana@gmail.com
However, the single cone was the most commonly investigated technique possibly due to the simpler and more popular approach for comparison purposes. ${ }^{1-3}$

The use of newer root filling materials containing bioactive substances in the recent practice could be due to the advantages, including ability to provide an effective seal, promote hard tissue formation and biocompatible. GuttaFlow Bioseal for example, is a silicone-based obturation material, has improved flow properties, does not require heat source to soften the gutta-percha (GP), expands slightly during setting and contains bioactive materials that enables hard tissue formation during healing process, making it suitable for sealing of the root canal system. With a setting time of approximately 12-16 minutes, this material is being 
accepted as a current approach in obturating the root canal system.

The obturation quality has been studied by many researchers in aspects of the presence of marginal gaps and voids. ${ }^{1-9}$ Marginal gaps are defined as a discontinuity at the interface made of two different materials while voids are defined as the vacant area surrounded by the same materials. ${ }^{5}$

During obturation procedure, the extrusion of root filling material beyond the apical foramen is sometimes inevitable, especially in patent root canal terminus. It has been suggested that the canal instrumentation or obturation should not extend beyond the apical foramen ${ }^{10}$ because obturation within the canal space correlate with higher success rates of root canal treatment. ${ }^{11}$ Although in certain cases, the extrusion of root filling material might not cause adverse tissue reactions and the tooth remains asymptomatic, ${ }^{12}$ but in some cases it can lead to other problems such as paraesthesia of the nerve, ${ }^{13,14}$ discomfort or pain ${ }^{15}$ and chronic inflammation. ${ }^{13,16}$

To date, the duration required to carry out obturation procedure has not been studied possibly due to little or no impact on the outcomes of the endodontically treated tooth. However, in endodontic retreatment, the duration required to evaluate the performance of retreatment file system, ${ }^{19}$ the removing of root filling material 18,20 and the amount of remnants remaining in the root canal ${ }^{17}$ have been investigated.

The aims of this study were to compare the obturated surface area, extrusion of root filling material beyond the apical foramen and duration taken for obturation between GuttaFlow Bioseal and RoekoSeal Automix root canal sealer as monocone obturation technique.

\section{MATERIALS AND METHODS}

\section{Preparation of samples}

This study was approved by the International Islamic University Malaysia Research Ethics Committee (IREC 2018-29).
A total of 4 samples for training session and 20 samples for actual study were selected based on the inclusion and exclusion criteria as follows. Inclusion criteria included single-rooted mandibular premolars, intact coronal tooth structure, no caries, no restoration, intact root, fully formed apices. Exclusion criteria were moderate to severely curved roots, external and internal resorption, severe attrition, root fracture, calcified canal and crack lines.

\section{Training session}

A training session was carried out to standardise each step of the procedures involving two undergraduate dental students under close supervision of an endodontist. This includes the demonstration on access cavity preparation, root canal preparation, obturation, tooth sectioning and observation under scanning electron microscope (SEM). Inter- and intra-examiner reliability was difficult to conduct due to the different samples, therefore, the procedures were assessed clinically and radiographically.

\section{Endodontic procedure}

The endodontic procedure on 20 samples was conducted by two undergraduate dental students as shown in Figure 1. Samples were mounted on silicone impression materials and preoperative radiographs were taken from two directions; mesio-distal and buccolingual to assess the status of the root canal.

A standard access cavity was prepared using a cavity access set (Dentsply Maillefer, Switzerland). Then, 25/.08 orifice opener HyFlex CM rotary file (Coltène) Whaledent) was used to preflare the coronal aspect of the canal. The root canal terminus was set at $0.5 \mathrm{~mm}$ short of the apical foramen using size $15 \mathrm{~K}$-file and confirmed with periapical radiograph. Then, the root canal was prepared with $20 / .06,25 / .06$ and 30/.06 HyFlex CM rotary files at $500 \mathrm{rpm}$ rotational speed and 2.5 $\mathrm{Ncm}$ torque level in accordance with the manufacturer's recommendation. The final root canal preparation was set at 30/.06 HyFlex CM rotary files because excessive root canal preparation removes the root dentine unnecessarily. By following standard root canal preparation, the size of apical foramen can be maintained. 
All samples were equally divided into Group 1 and 2 $(n=10)$. In Group 1, the obturation was done using GuttaFlow Bioseal (Coltène/Whaledent) and a 30/.06 GP cone. In Group 2, the obturation was done using RoekoSeal Automix root canal sealer (Coltène/ Whaledent) and a 30/.06 GP cone. In both groups, the GuttaFlow Bioseal and RoekoSeal Automix root canal sealer were delivered into the prepared root canal using a special tip, then a 30/.06 GP cone was fitted into the root canal. A heated endodontic plugger was used to cut the GP at the cementoenamel junction (CEJ) and the GP was compacted vertically to $2 \mathrm{~mm}$ below the CEJ level and the surface of GP appeared to be smooth.

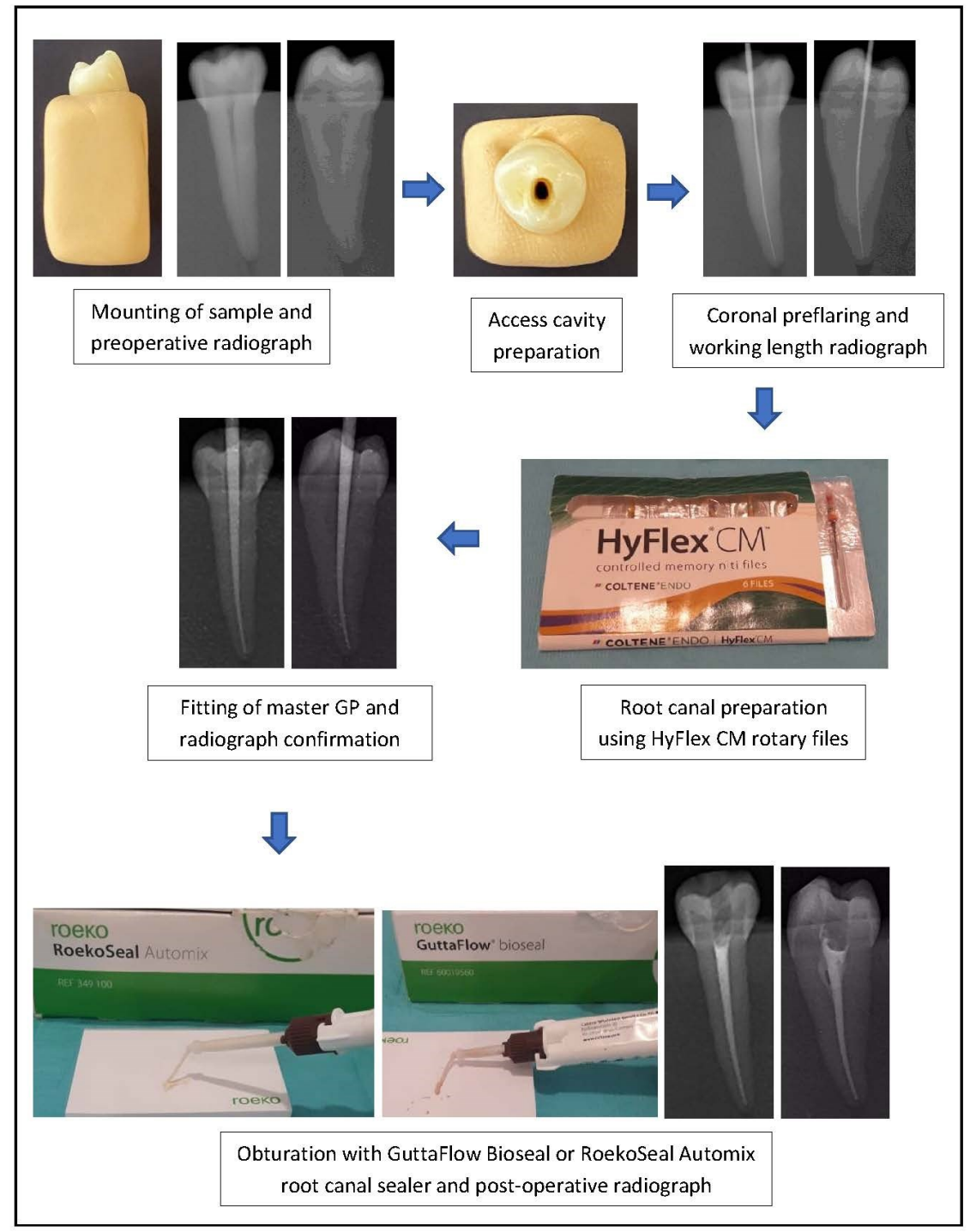

Figure 1 Endodontic procedure involving access cavity preparation, root canal preparation and obturation.

Duration of the obturation procedure was recorded with a digital timer starting from the delivery of root filling material into the root canal until complete removal of the excess material from the access cavity. Obturation radiograph was taken immediately after the obturation procedure to assess the presence of material extruding beyond the apical foramen.

The cavity access was restored with composite resin (NTPremium, Coltene). Then, all samples were stored in separate vials at room temperature with $100 \%$ humidity for 7 days to ensure complete setting of the root filling materials.

\section{Tooth sectioning and observation under scanning electron microscope}

The roots of all samples were sectioned perpendicular to the long axis of the tooth with a diamond saw cutting machine (Isomet 1000, Buehler Ltd., Lake Bluff, IL) under distilled water to obtain 3 root segments; the apical, middle and coronal. Debris was removed and the 
resected roots were smoothed with 600-grit wet silicon carbide sandpaper (Leco, St. Joseph, MI, USA) before being observed under SEM. The resected roots were dehydrated in $25 \%, 50 \%$ and $75 \%$ ethanol for 20 minutes each, in 95\% ethanol for 30 minutes and in $100 \%$ ethanol for 60 minutes, then dried by placing on filter paper inside a covered glass vial at room temperature for 24 hours.

The resected roots were mounted on brass stubs and sputter-coated with thin gold coating using Sputter Coater Machine. The coronal surface of all resected roots was observed under SEM (Zeiss EVO50, Germany) at 20x magnification.

\section{SketchAndCalc Area Calculator software}

The SEM images of all root segments were transferred to the SketchAndCalc Area Calculator software. Obturated surface area, marginal gaps and voids were carefully sketched by following the outline of root canal, root filling material and empty spaces within the root filling material. The values of obturated surface area, marginal gaps and voids were automatically generated after each drawing. These values were recorded for calculation of the volumetric percentage as follows:

Volumetric percentage of the obturated surface area $=$

Value of the obturated surface area - Value of the void(s)*

Value of the root canal space
*If present

\section{Data analysis}

The data was analysed using SPSS version 25.0. MannWhitney $U$ test with a significance level of $p<0.05$ was conducted to evaluate the volume of obturated surface area in Group 1 and 2 at three different levels; the apical, middle, coronal. Fisher's exact test was carried out to evaluate the extrusion of root filling material beyond the apical foramen in Group 1 and 2 . Independent sample t-test was performed to compare the duration of obturation procedure in Group 1 and 2.

\section{RESULTS}

The resected roots observed under SEM at 20x magnification and the images of obturated surface are evaluated using SketchAndCalc Area Calculator software were shown in Figure 2 and 3, respectively.

The median scores of the obturated surface area at the apical and middle regions between two groups did not show statistically significant differences, however, a statistically significant difference was observed at the coronal region [Table 1].

Table 1 Mann-Whitney u test for obturated surface areas at the apical, middle and coronal regions.

\begin{tabular}{llll}
\hline $\begin{array}{l}\text { Obturated } \\
\text { surface area }\end{array}$ & $\begin{array}{l}\text { Group 1 } \\
\text { Median (IQR) }\end{array}$ & $\begin{array}{l}\text { Group 2 } \\
\text { Median (IQR) }\end{array}$ & $p$ value \\
\hline Apical & $86.51( \pm 16.08)$ & $83.00( \pm 11.73)$ & 0.406 \\
Middle & $90.48( \pm 8.70)$ & $87.35( \pm 8.80)$ & 0.140 \\
Coronal & $93.00( \pm 6.66)$ & $83.39( \pm 14.36)$ & 0.016 \\
\hline
\end{tabular}

Group 1 and 2 showed no statistically significant difference with regards to the extrusion of root filling material beyond the apical foramen [Table 2].

Table 2 Fisher's exact test for extrusion of root filling material beyond the apical foramen.

\begin{tabular}{llll}
\hline \multirow{2}{*}{$\begin{array}{c}\text { Obturation } \\
\text { techniques }\end{array}$} & \multicolumn{2}{l}{$\begin{array}{l}\text { Extrusion of obturation } \\
\text { material n }(\%)\end{array}$} & \multirow{2}{*}{ p value } \\
\cline { 2 - 3 } & No & Yes & \\
\hline Group 1 & $3(30 \%)$ & $7(70 \%)$ & 1.00 \\
Group 2 & $3(30 \%)$ & $7(70 \%)$ & \\
\hline
\end{tabular}

* IQR: Interquartile range

The mean duration of obturation procedure between two groups showed statistically significant difference [Table 3] where the obturation procedure in Group 1 took $8.6 \%$ longer compared to Group 2.

Table 3 Independent sample t-test for the duration (in second) of obturation procedure.

\begin{tabular}{llll}
\hline Mean (SD) & & $\begin{array}{l}\text { Mean difference } \\
(95 \% \mathrm{Cl})\end{array}$ & $p$ value \\
\hline Group 1 & Group 2 & $\begin{array}{l}11.90 \\
(1.402,23.398)\end{array}$ & 0.027 \\
\hline $\begin{array}{llll}149.50 \\
( \pm 17.11)\end{array}$ & $\begin{array}{l}137.60 \\
( \pm 23.08)\end{array}$ & & \\
\hline
\end{tabular}




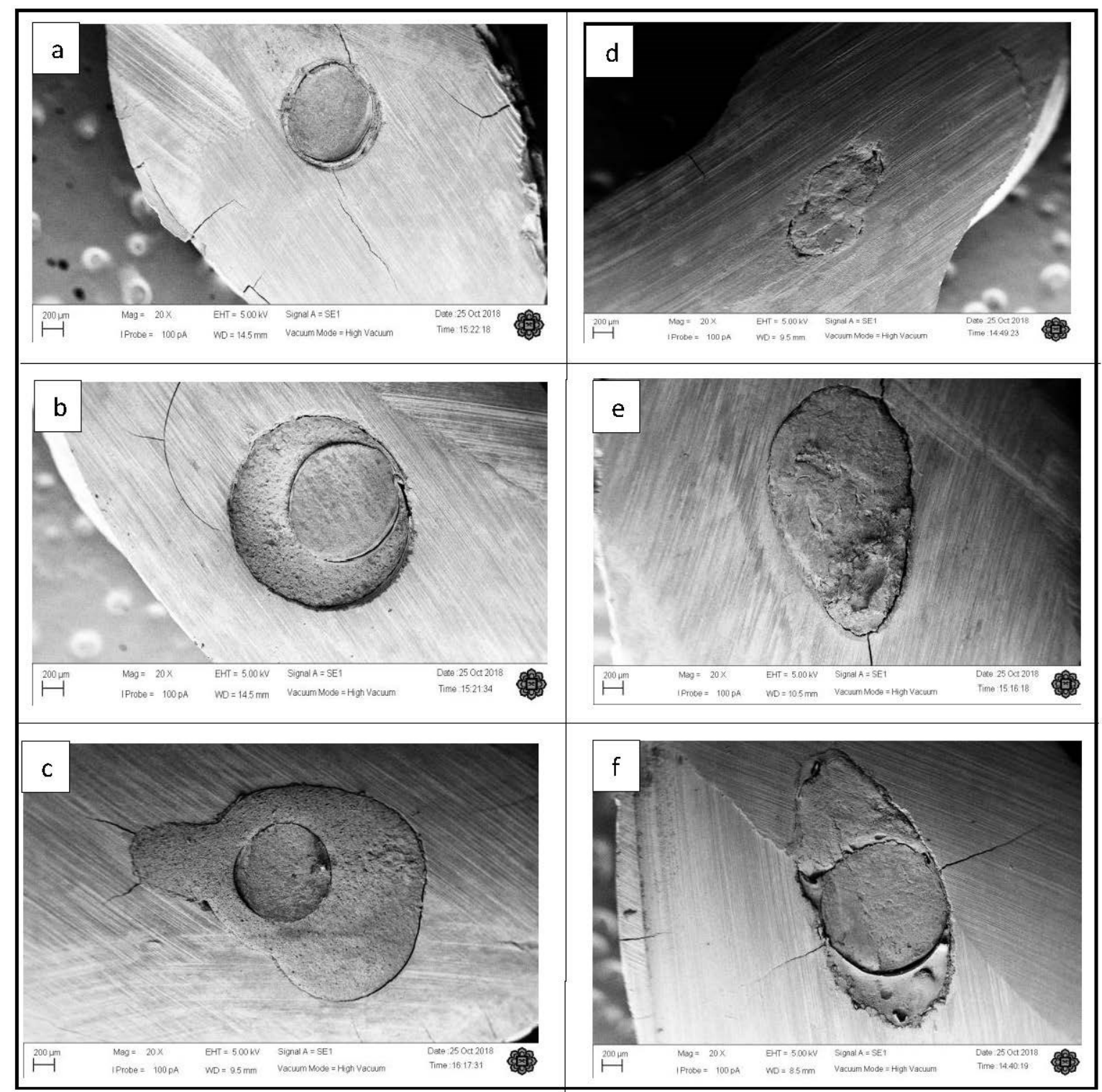

Figure 2 SEM images in Group 1 at the a) apical, b) middle, c) coronal, and in Group 2 at the d) apical, e) middle, f) coronal regions.

\section{DISCUSSION}

The present study is the first research evaluating multiple aspects related to the obturation procedure using GuttaFlow Bioseal and RoekoSeal Automix root canal sealer as monocone obturation technique in singlerooted mandibular premolars.

Previous studies on GuttaFlow Bioseal have reported its penetration into the dentinal tubules following the agitation of root canal irrigant, ${ }^{21}$ cytotoxic potential, ${ }^{22,23}$ physicochemical properties, ${ }^{24-25}$ sealing ability ${ }^{26}$ and osteogenic potential 27 but have not reported some aspects investigated in this study. GuttaFlow Bioseal is currently available for use in obturation of the root canal system, despite lacking of robust scientific reports.
Therefore, direct comparison of our findings to the previous research was not possible.

The presence of marginal gaps and/or voids in the present study could be seen in almost all samples and this was in agreement with the previous studies 3,8 that demonstrated the presence of marginal gaps and voids in all their samples. Due to the complexity of root canal system, a perfect adaptation of root filling material to the root canal wall is difficult to achieve regardless of the obturation technique used. The exception is with thermoplastic GP which uniformly adapts to the irregularities of the root canal walls with only minor voids as demonstrated by previous study. ${ }^{4}$ 


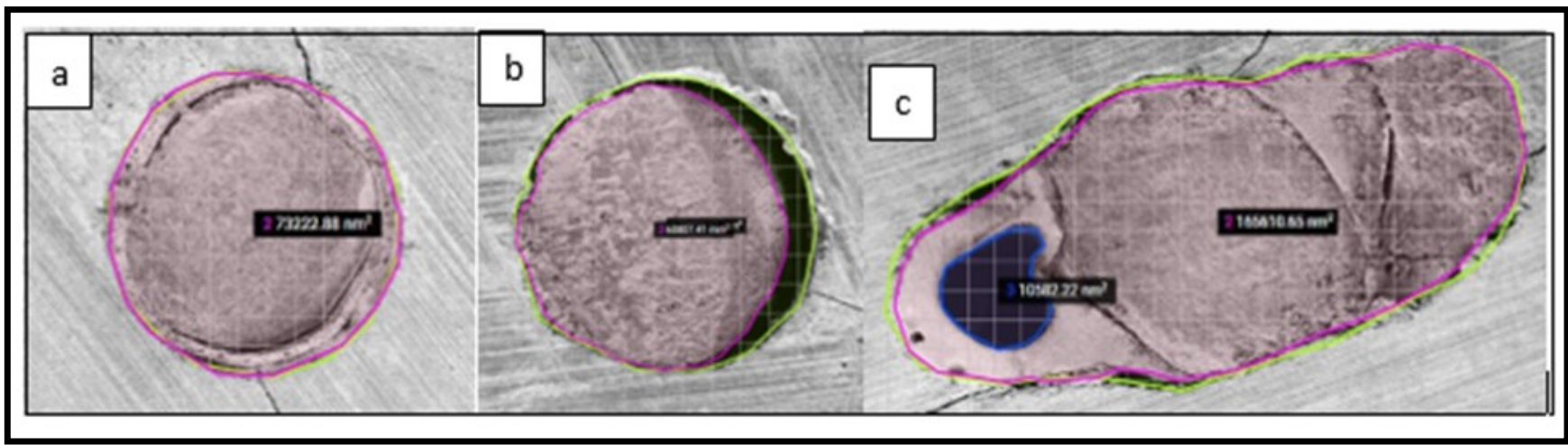

Figure 3 Evaluation using SketchAndCalc Area Calculator software showing a) well-adapted obturation, b) marginal gap c) combination of marginal gaps and voids.

The obturated surface area at three different levels (apical, middle, coronal) was evaluated because of different root canal morphology and this approach was corroborated with the previous studies.9,21 Although multiple slices have more thorough evaluation, but this approach is more time-consuming and costly, particularly when it involves larger sample size. Therefore, this approach is not suitable in the present study because of limited sample size.

The present study used SEM to observe the obturated surface area which was congruent with the previous studies $1,3-5,8$ because of the ability to produce high resolution images and higher magnification compared with the conventional microscope. This approach is appropriate for evaluating the irregular surfaces due to the depth of the focal field and the degree of magnification obtainable. ${ }^{4}$ However, the limitation of this approach is that SEM operates under high vacuum and the genuine gaps can be impossible to distinguish from the artificial gaps created during vacuum desiccation. ${ }^{28}$ An alternative approach for imaging is to use a Confocal Laser Scanning Microscopy (CLSM) which does not require sample gold sputter-coating and is able to preserve the samples in their natural state. CLSM also does not require samples processing and the observations can be made under close to normal conditions. Thus, CLSM does not produce technique artifacts such as false gaps and also is a non-destructive approach 29 due to the optical sectioning and not physical sectioning technique that enables the examination of the samples with enhanced clarity. ${ }^{30}$ However, the limitation of CLSM is that the confocal imaging is dependent on the level of resolution, scan time and the risk of photo destruction of the sample.
The use of higher resolution is more time-consuming for the scanning and the longer the fluorophore is exposed to the laser. Increasing the level of resolution does not result in an increase in useful biological information of the sample. Micro CT is also a nondestructive approach but the limitation of this is that the presence of voids in the root filling material and the marginal gaps between the root filling material and root canal wall could not be differentiated effectively ${ }^{5}$ as demonstrated in the previous study that the presence of void observed using Micro CT did not correspond with the observation under stereomicroscope possibly due to the inadequate resolution to detect the small voids. ${ }^{9}$ To date, methods of evaluating the obturated surface area remain debatable although some authors opt for double methods 5, 7, 9 to present more reliable data. Perhaps, in future research, multiple techniques can be combined to evaluate the obturated surface area of the entire root canal system.

Our findings on the obturated surface area suggested that at the apical and middle regions, GuttaFlow Bioseal and RoekoSeal Automix root canal sealer as monocone obturation technique were comparable. However, at the coronal region, the use of GuttaFlow Bioseal showed $11.5 \%$ better coverage than the RoekoSeal Automix root canal sealer. This could be due to two possible reasons; 1) Root canal morphology. The apical and middle regions are much narrower in dimension and requires less root filling material to conform to the root canal, unlike the coronal region that is much wider in dimension and requires more root filling material to conform to the root canal. 2) When the root filling material is delivered into the root canal during the obturation procedure, adaptability of the root filling 
material to the root canal wall is difficult to assess because of the internal structure that cannot be directly observed. Perhaps, delivery of GuttaFlow Bioseal into the root canal was conducted well, which may explain why the obturated surface area in this region was better.

In the future research, the use of magnification devices can provide a better view of the root canal, thus permitting the efficient delivery of root filling material into the root canal. The consistency and flowability of both root filling materials were not investigated as it is beyond the scope of the present study. These aspects are worth investigating in the future to confirm the findings.

Our findings on the extrusion of root filling material beyond the apical foramen using GuttaFlow Bioseal and RoekoSeal Automix root canal sealer as monocone obturation technique were equivalent as the $p$ value is more than 0.05 [Table 2]. This could be attributed to the similar technique used for delivering the root filling material into the root canal and the material viscosity but the later was not possible to confirm because of beyond the scope of the present study.

The duration of obturation procedure provides a general picture of the working time needed to obturate the root canal system particularly when using newer root filling materials. Our findings showed that the obturation using GuttaFlow Bioseal took 8.6\% longer than the RoekoSeal Automix root canal sealer. This could be due to the greater amount of GP mass resulting from the combination of GuttaFlow Bioseal and a GP cone. Hence, removal of the excess material took longer compared to the other group. Apart from this, the time required to obturate the root canal could be influenced by the root canal morphology which vary from tooth to tooth and the operators' skills and experience. Perhaps, these aspects require further investigation to help the clinician in better understanding on factors determining the duration needed to carry out the obturation procedure.

GuttaFlow Bioseal and RoekoSeal Automix root canal sealer as monocone obturation technique showed similarities in certain aspects and differences in other aspects. Based on these findings, both root filling materials can be implemented for obturation of root canal system depending on the clinical cases, clinician preferences and material availability. It is hoped that further research in this field will improve the existing limitations in both obturation techniques for future clinical practice.

\section{CONCLUSIONS}

Within the limitations of the present study, the conclusions that could be made are:

1. The obturated surface area at the apical and middle regions using GuttaFlow Bioseal and RoekoSeal Automix root canal sealer was comparable, however at the coronal region, GuttaFlow Bioseal showed $11.5 \%$ better coverage compared to the RoekoSeal Automix root canal sealer.

2. The extrusion of root filling material beyond the apical foramen using GuttaFlow Bioseal and RoekoSeal Automix root canal sealer was equivalent.

3. The obturation procedure using GuttaFlow Bioseal took 8.6\% longer than the RoekoSeal Automix root canal sealer.

\section{ACKNOWLEDGEMENTS}

The authors would like to express sincere gratitude to Dr. Azrul Fazwan Bin Kharuddin for evaluating the obturated surface area using SketchAndCalc Area Calculator software.

This research was funded by the Research Initiative Grant Scheme 2017 from International Islamic University Malaysia (RIGS 2017-063-0638).

Conflict of interest: There are no conflicts of interest.

\section{REFERENCES}

1. James BL, Brown CE, Legan JJ, Moore BK, Vail MM. An in vitro evaluation of the contents of root canals obturated with gutta percha and AH-26 sealer or Resilon and Epiphany sealer. J Endod. 2007; 33(11): 1359-1363.

2. Al-Afifi NA, Abdullah M, Al-Amery SM, Abdulmunem M. Comparison between guttapercha and resin-coated gutta-percha using different 
obturation techniques. J Appl Biomater Funct

Mater. 2016; 14(3): e307-313.

3. Adhikari HD, Jain S. Scanning electron microscopic evaluation of marginal adaptation of AH-Plus, GuttaFlow, and RealSeal at apical onethird of root canals - Part II: Core-sealer interface. J Conserv Dent. 2018; 21(1): 90-94.

4. Torabinejad M, Skobe Z, Trombly PL, Krakow AA, Grøn P, Marlin J. Scanning electron microscopic study of root canal obturation using thermoplasticized gutta-percha. J Endod. 1978; 4 (8): 245-250.

5. Selem LC, Li GH, Niu LN, Bergeron BE, Bortoluzzi EA, Chen JH, et al. Quality of obturation achieved by a non-gutta-percha-based root filling system in single-rooted canals. J Endod. 2014; 40(12): 2003-2008.

6. Gok T, Capar ID, Akcay I, Keles A. Evaluation of Different Techniques for Filling Simulated Cshaped Canals of 3-dimensional Printed Resin Teeth. J Endod. 2017; 43(9): 1559-1564.

7. Huang Y, Orhan K, Celikten B, Orhan AI, Tufenkci P, Sevimay S. Evaluation of the sealing ability of different root canal sealers: a combined SEM and micro-CT study. J Appl Oral Sci. 2018; 26: e20160584.

8. Jain S, Adhikari HD. Scanning electron microscopic evaluation of marginal adaptation of AH-plus, GuttaFlow, and RealSeal at apical onethird of root canals - Part I: Dentin-sealer interface. J Conserv Dent. 2018; 21(1): 85-89.

9. Kim JA, Hwang YC, Rosa V, Yu MK, Lee KW, Min KS. Root Canal Filling Quality of a Premixed Calcium Silicate Endodontic Sealer Applied Using Gutta-percha Cone-mediated Ultrasonic Activation. J Endod. 2018; 44(1): 133-138.

10. Wu MK, Wesselink PR, Walton RE. Apical terminus location of root canal treatment procedures. Oral Surg Oral Med Oral Pathol Oral Radiol Endod. 2000; 89(1): 99-103.

11. Schaeffer MA, White RR, Walton RE. Determining the optimal obturation length: a meta-analysis of literature. J Endod. 2005; 31(4): 271-274.

12. Hubbe KL, de Oliveira KV, Coelho BS, BarattoFilho F. AH Plus extrusion into periapical tissue: literature review of main related properties and report of clinical cases. RSBO. 2016; 13(4): 280288.
13. Ektefaie MR, David HT, Poh CF. Surgical resolution of chronic tissue irritation caused by extruded endodontic filling material. J Can Dent Assoc. 2005; 71(7): 487-490.

14. González-Martín M, Torres-Lagares D, GutiérrezPérez JL, Segura-Egea JJ. Inferior alveolar nerve paresthesia after overfilling of endodontic sealer into the mandibular canal. J Endod. 2010; 36(8): 1419-1421.

15. Brooks JK, Kleinman JW. Retrieval of extensive gutta-percha extruded into the maxillary sinus: use of 3-dimensional cone-beam computed tomography. J Endod. 2013; 39(9): 1189-1193.

16. Suzuki P, Souza Vd, Holland R, Gomes-Filho JE, Murata SS, Dezan Junior E, et al. Tissue reaction to Endométhasone sealer in root canal fillings short of or beyond the apical foramen. J Appl Oral Sci. 2011; 19: 511-516.

17. Cunha RS, De Martin AS, Barros PP, da Silva FM, Jacinto RC, Bueno CE. In vitro evaluation of the cleansing working time and analysis of the amount of gutta-percha or Resilon remnants in the root canal walls after instrumentation for endodontic retreatment. J Endod. 2007; 33(12): 1426-1428.

18. Hess D, Solomon E, Spears R, He J. Retreatability of a bioceramic root canal sealing material. J

Endod. 2011; 37(11): 1547-1549.

19. Beasley RT, Williamson AE, Justman BC, Qian F. Time required to remove guttacore, thermafil plus, and thermoplasticized gutta-percha from moderately curved root canals with protaper files. J Endod. 2013; 39(1): 125-128.

20. Kim SR, Kwak SW, Lee JK, Goo HJ, Ha JH, Kim HC. Efficacy and retrievability of root canal filling using calcium silicate-based and epoxy resin-based root canal sealers with matched obturation techniques. Aust Endod J. 2019; 1-9.

21. Akcay M, Arslan H, Durmus N, Mese M, Capar ID. Dentinal tubule penetration of AH Plus, iRoot SP, MTA fillapex, and guttaflow bioseal root canal sealers after different final irrigation procedures: A confocal microscopic study. Lasers Surg Med. 2016; 48(1): 70-76.

22. Collado-González M, Tomás-Catalá CJ, OñateSánchez RE, Moraleda JM, Rodríguez-Lozano FJ. Cytotoxicity of GuttaFlow Bioseal, GuttaFlow2, MTA Fillapex, and AH Plus on Human 
Periodontal Ligament Stem Cells. J Endod. 2017;

43(5): 816-822.

23. Saygili G, Saygili S, Tuglu I, Davut Capar I. In

Vitro Cytotoxicity of GuttaFlow Bioseal,

GuttaFlow 2, AH-Plus and MTA Fillapex. Iran

Endod J. 2017; 12(3): 354-359.

24. Camargo RV, Silva-Sousa YTC, Rosa R, Mazzi-

Chaves JF, Lopes FC, Steier L, et al. Evaluation of

the physicochemical properties of silicone- and

epoxy resin-based root canal sealers. Braz Oral

Res. 2017; 31: e72.

25. Tanomaru-Filho M, Torres FFE, Chavez-Andrade

GM, de Almeida M, Navarro LG, Steier L, et al.

Physicochemical Properties and Volumetric

Change of Silicone/Bioactive Glass and Calcium

Silicate-based Endodontic Sealers. J Endod. 2017;

43(12): 2097-2101.

26. Gandolfi MG, Karami Shabankare A, Zamparini F,

Prati C. Properties of a novel polydimethylsiloxane

endodontic sealer. Giornale Italiano di

Endodonzia. 2017; 31(1): 35-43.

27. Hoikkala NJ, Wang X, Hupa L, Smatt JH, Peltonen

J, Vallittu PK. Dissolution and mineralization

characterization of bioactive glass ceramic

containing endodontic sealer Guttaflow Bioseal.

Dent Mater J. 2018; 37(6): 988-994.

28. De Munck J, Van Landuyt K, Peumans M,

Poitevin A, Lambrechts P, Braem M, et al. A

critical review of the durability of adhesion to

tooth tissue: methods and results. J Dent Res.

2005; 84(2): 118-132.

29. Tay FR, Sidhu SK, Watson TF, Pashley DH. Water -dependent Interfacial Transition Zone in Resin-modified Glass-ionomer Cement/Dentin Interfaces. J Dent Res. 2004; 83(8): 644-649.

30. Claxton NS, Fellers TJ, Davidson MW.

Microscopy, Confocal. In Encyclopedia of Medical Devices and Instrumentation, J G Webster (Ed)2006. 